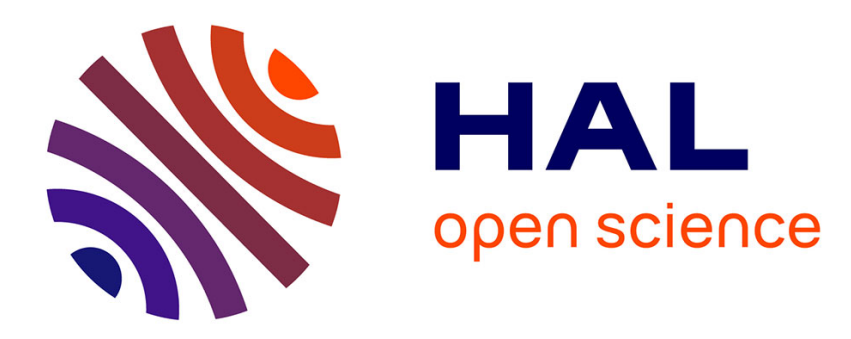

\title{
Light beam positional modulation by gel rod dilatational mode
}

\author{
J.-C. Bacri, J. Dumas
}

\section{To cite this version:}

J.-C. Bacri, J. Dumas. Light beam positional modulation by gel rod dilatational mode. Revue de Physique Appliquée, 1980, 15 (4), pp.875-878. 10.1051/rphysap:01980001504087500 . jpa-00244799

\section{HAL Id: jpa-00244799 https://hal.science/jpa-00244799}

Submitted on 1 Jan 1980

HAL is a multi-disciplinary open access archive for the deposit and dissemination of scientific research documents, whether they are published or not. The documents may come from teaching and research institutions in France or abroad, or from public or private research centers.
L'archive ouverte pluridisciplinaire HAL, est destinée au dépôt et à la diffusion de documents scientifiques de niveau recherche, publiés ou non, émanant des établissements d'enseignement et de recherche français ou étrangers, des laboratoires publics ou privés. 


\title{
Light beam positional modulation by gel rod dilatational mode
}

\author{
J.-C. Bacri and J. Dumas \\ Laboratoire d'Ultrasons $\left({ }^{*}\right)$, Université Pierre-et-Marie-Curie, \\ Tour 13, 4 place Jussieu, 75230 Paris Cedex 05, France
}

(Reçu le 2 octobre 1979, révisé le 6 décembre 1979, accepté le 12 décembre 1979)

\begin{abstract}
Résumé. - Les modes de gonflement d'un barreau de gel sont utilisés à basse fréquence $(20-2000 \mathrm{~Hz})$ pour obtenir la déflection d'un faisceau laser à l'aide d'un montage très simple et peu onéreux. Une déflection de $15^{\circ}$ est obtenue à $140 \mathrm{~Hz}$ avec une puissance électrique de $9 \mathrm{~mW}$.
\end{abstract}

Abstract. - An elastic dilatational mode at very low frequency $(20-2000 \mathrm{~Hz})$ in a gel rod is used to deflect a laser beam in a simple and very low price set-up. A $15^{\circ}$ deflection is observed at $140 \mathrm{~Hz}$ with a electrical power of $9 \mathrm{~mW}$.

1. Introduction. - A gel is an infinite crosslinked polymer imbedded in a fluid solvent [1]. The polymer weight concentration which is able to give gelation varies between $1 \%$ and $20 \%$, depending on the kind of chemical species used.

This particular media reacts at low mechanical frequencies as an isotropic solid : it is almost incompressible with the bulk modulus of the solvent $\left(K_{\mathrm{s}} \simeq 2 \times 10^{10}\right.$ dynes $\left.\mathrm{cm}^{-2}\right)$ but its shear modulus $\mu_{\mathrm{p}}$ is very low and reflects only elastic properties of the polymer network $[2,3,4]\left(\mu_{\mathrm{p}} \simeq 2 \times 10^{5}\right.$ dynes cm $\mathrm{cm}^{-2}$ for a $10 \%$ polyacrylamide gel).

This very low elastic constant value gives the possibilities to excit with hight efficiency dilatational modes at low frequencies in rodlike samples of gel, with noticeally high deformation compared to those obtained in normal solids : for a given stress amplitude on the end surface the radial deformation obtained in gel is about $10^{5}$ greater than in normal solid.

The aim of this paper is to describe a system based on the use of dilatational modes in gel, to deflect a light beam. Some $\mathrm{mW}$ of electrical power are only needed to obtain a deflection of some degrees. The system, in the simple form described here, can be operated between 20 and $2000 \mathrm{~Hz}$.

2. Theory. - A solid cylinder with clamped end faces and perfectly free lateral surface shows dilatational modes which has been studied for a long time [5,

$\left(^{*}\right)$ Associated with the Centre National de la Recherche Scientifique.
$6,7]$. For the simplest of them, two displacement components $u_{r}$ and $u_{z}$ are relevant, with the axis $z$ along the axis of the cylinder, and $r$ the radial distance from it.

For a standing wave resonance,

$$
\begin{aligned}
& u_{r}=A\left(k_{0} R, k_{0} r\right) \cos k_{0} z \exp i \omega_{0} t \\
& u_{z}=B\left(k_{0} R, k_{0} r\right) \sin k_{0} z \exp i \omega_{0} t
\end{aligned}
$$

The amplitudes $A$ and $B$ are complicated functions of the distance $r$ from the axis involving the elastic constants of the material, $k_{0}=2 \pi / \lambda$ is the wave vector, $R$ the cylinder radius and $\omega_{0}$ the frequency.

Considering only the surface of the rod, the standing wave pattern implies that for some positions $z_{0}$, a circle $r=R$, has no radial components of movements : these points are given by $\cos k_{0} z_{0}=0$.

In the main longitudinal section of the rod and for $z=z_{0}$, the tangential plane on the surface makes at any time an angle $\theta$ with the axis of the rod defined by

$$
\operatorname{tg} \theta=\left.\frac{\partial u_{r}}{\partial z}\right|_{\substack{r=R \\ z=z 0}}=k_{0} u_{r=R} .
$$

The value $u_{r=R}$ appearing in this formula is the maximum amplitude of the radial component of displacement at the surface when the rod is driven at resonance on the particular mode considered. This high value is obtained on the rod surface at locations just between $z_{0}$ points we have mentioned. If $Q$ is the 
mechanical quality factor of the resonance and $u_{\mathrm{i}}^{0}$ the radial driving amplitude outside resonance :

$$
u_{r=R}=Q u_{r}^{0} .
$$

$Q$ is related to the amplitude attenuation $\alpha$ of the mode by $[8]$ for $\lambda>R$ :

$$
Q=\frac{\pi}{\lambda \alpha} \quad \text { with } \quad \alpha=\frac{2 \pi^{2} v^{2}}{\rho v^{3}} \eta
$$

$\rho$ is the material density, $v$ the phase velocity, $v_{0}=2 \pi \omega_{0}=$ resonance frequency, $\eta$ is the effective viscosity damping the mode. Then

$$
\operatorname{tg} \theta=k_{0} Q u_{r}^{0}=\frac{\rho v}{\eta} u_{r}^{0} .
$$

This formula is not directly usable : the excitation of the mode is made through an $u_{z}^{0}$ displacement applied on one end face of the rod. But the ratio $\left.\frac{u_{r}^{0}}{u_{z}^{0}}\right|_{r=R}$ is known to be between 0.5 and 2.4 depending of the elastic constants of the rod and of the ratio $R / \lambda$, as is shown for instance in [7]: we take $u_{r}^{0} / u_{z}^{0} \simeq 1$ and

$$
\operatorname{tg} \theta \simeq \frac{\rho}{\eta} v u_{z}^{0} .
$$

3. Expected order of magnitude of the deflection. We will use this surface deformation to deflect a light beam at the frequency of the elastic mode in the rod : it is possible in a gel rod because the elastic constant is so small compared to other solid $\left(10^{5}\right.$ dynes $/ \mathrm{cm}^{2}$ instead of $10^{10}$ dynes $/ \mathrm{cm}^{2}$ ). For a given stress amplitude on the end surface of the rod, the deformation $u_{r}$ and then $\operatorname{tg} \theta$ is $10^{5}$ greater in gel than in glass, for instance.

The transducer used is an electromagnetic shaker with $3.5 \Omega$ coil impedance in the frequency range $20 \mathrm{~Hz}$ to $2000 \mathrm{~Hz}$ : a power of $35 \mathrm{~mW}$ is needed to obtain a $40 \mu \mathrm{m}$ maximum amplitude $u_{z}^{0}$ at the frequency of $140 \mathrm{~Hz}$.

The shear viscosity of the polymer network which damped the dilatational.mode has been mesured in [3] : $\eta \simeq 1 \mathrm{P}$. The corresponding velocity is $v=230 \mathrm{~cm} / \mathrm{s}$ with $\rho \simeq 1 \mathrm{~g} / \mathrm{cm}^{3}: \operatorname{tg} \theta \simeq 1$, corresponding to a deflection angle $\theta \simeq 45^{\circ}$.

4. Experimental. - 4.1 SAMPle PReparation. The polyacrylamide gel was prepared in the following way. $30 \mathrm{~g}$ acrylamide and $0.8 \mathrm{~g} \mathrm{~N}, \mathrm{~N}^{\prime}$-methylene-bisacrylamide (a crosslinking agent) were dissolved in distilled water to make up a $100 \mathrm{ml}$ solution (solution A). $3.33 \mathrm{ml}$ of this solution $A$ was transferred into a test-tube; $330 \mu \mathrm{l}$ of $10 \%$ ammonium persulfate solution was added with distilled water to make up a $10 \mathrm{ml}$ solution. $5 \mu \mathrm{l}$ of tetraethyl-N-ethylene-diamine was further added to initiate the copolymerization of the acrylamide and bis-acrylamide solution. The gelation occurred $10 \mathrm{~min}$. later. The problem is to remove the gel from the test tube with no damage. This is done by carefully introducing water between the gel and the tube wall with a syringe. The sample is cut to the desired size with a scalpel and a thin nylon wire.

4.2 Measurements. - The experimental set up is shown in figure 1. A cylindrical rod is made from $10 \%$ polyacrylamide gel of which we know already the physical characteristics from our study in ref. [3]. The sample $(l: 16 \mathrm{~mm}, \varnothing=16 \mathrm{~mm})$ is excited on one end face by an electromagnetic transducer able to vibrate from $20 \mathrm{~Hz}$ to $2000 \mathrm{~Hz}$ with a maximum absorbed power of $9 \mathrm{~W}$. The other end face is damped by an other transducer, which holds the rod without squeezing it notably and acts as a resonance monitor detecting the transmission maxima of the signal. This transducer is used for convenience and can be replace by a solid holder. The lateral surface of the rod is kept perfectly free. The rod is driven into mechanical resonance between $\sim 70 \mathrm{~Hz}$ and $2000 \mathrm{~Hz}$.

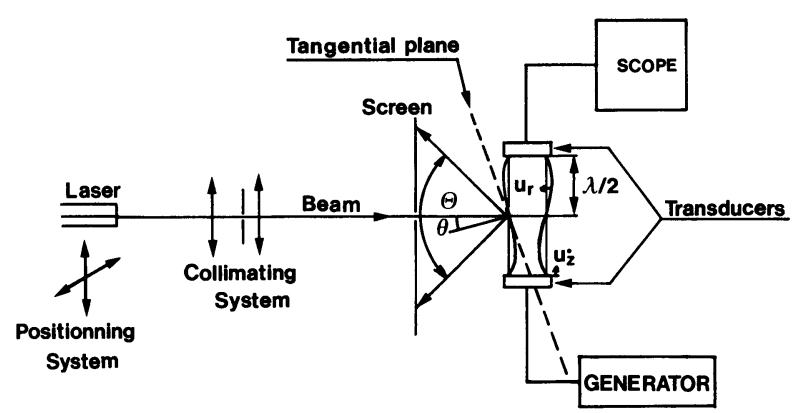

Fig. 1. - Experimental set-up.

A helium-neon laser beam correctly collimated to a diameter of about $0.5 \mathrm{~mm}$ is incident on the rod and is travelling very closely in the diametral symmetry plane of the rod. We observe the specular reflection of the beam from the lateral surface, on a screen : the amplitude of the beam deflection is measured in function of the frequency and the power which feed the sonic transducer. The laser can be adjusted in position to be incident on a $u_{r}=0$ part of the surface, where the deflection is then maximum. This procedure should be made for each frequency used. The $70 \mathrm{~Hz}$ excitation frequency corresponds to the fundamental mode for the length of the sample used : $u_{r}=0$ only at the ends of the rod and this frequency cannot be used simply for the deflection system. Then, measurements begin around $140 \mathrm{~Hz}$ where a $u_{r}=0$ point is found at half-length of the rod.

The cylindrical lens effect makes the reflected light to have a linelike shape perpendicular to the main axis of the gel rod. Two kinds of measurement have been made :

a) We measure the total deflection angle $\Theta=4 \theta$ of the beam in function of the frequency, when the electrical power on the excitation transducer is kept 


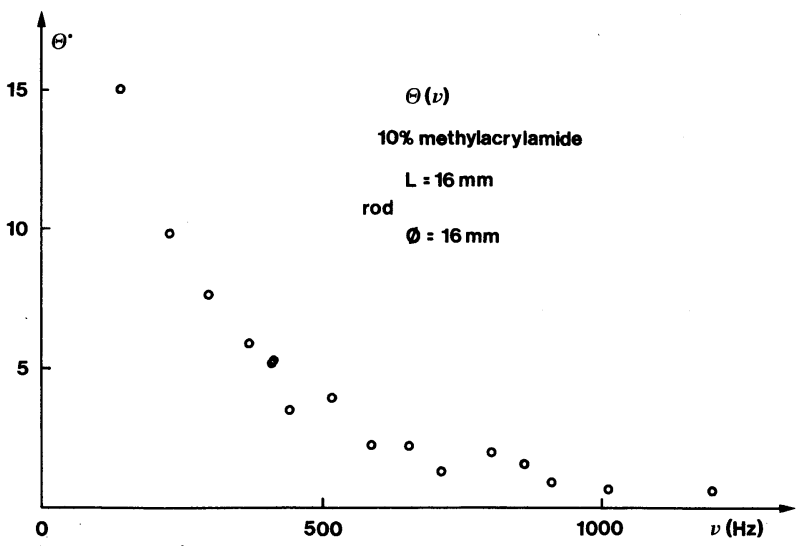

Fig. 2. - Total deflection angle plotted versus the frequency for a constant excitation power $(9 \mathrm{~mW})$. Each experimental point corresponds to a mechanical resonance peak of the gel sample.

constant to $9 \mathrm{~mW}$. Between $140 \mathrm{~Hz}$ and $2000 \mathrm{~Hz}$ we observe a certain number of resonance modes. At higher frequency, some modes still exist but the effect is small and not mentioned in figure 2 which gives the result. The deflection angle $\theta$ is decreasing with the frequency but is yet $0.5^{\circ}$ near $2000 \mathrm{~Hz}$, which is still usable. In figure 3 the frequencies of the resonance modes have been drawn in function of the order of the resonance, knowing that the fundamental near $70 \mathrm{~Hz}$ is not observed : the right line obtained shows that the dilatational mode is not dispersive in the region of ratio $R / \lambda, R$ radius of the rod, which we work in. This result has already been obtained elsewhere [3].

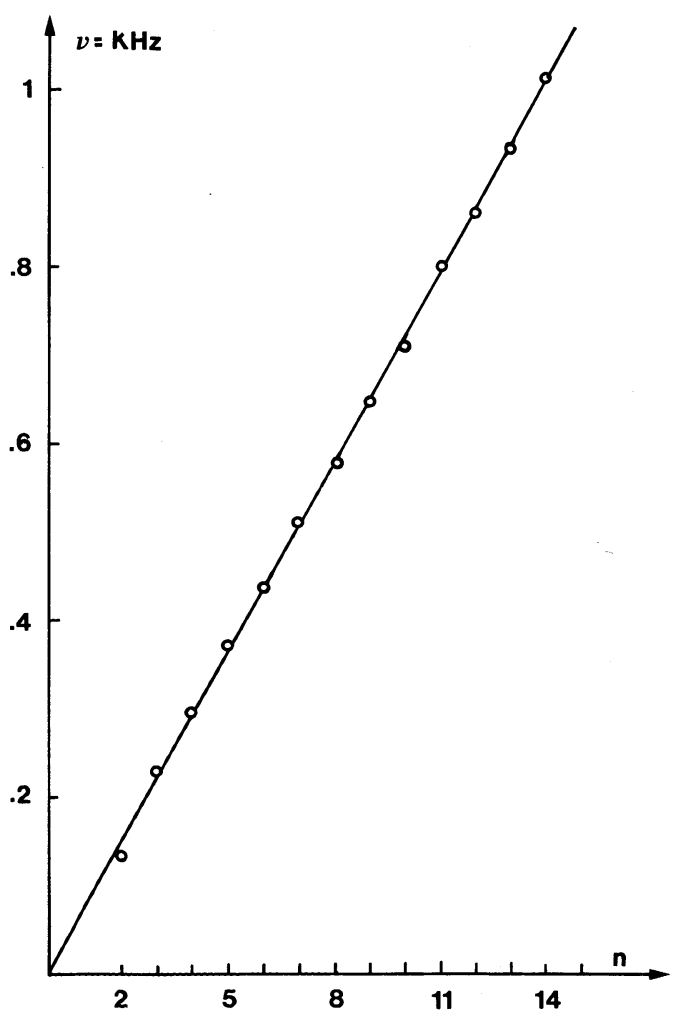

Fig. 3. - Resonance frequencies in function of order of modes. b) With the same system the transducer is set at $140 \mathrm{~Hz}$, frequency which gives the maximum deflection, and is driven at increasing power to $70 \mathrm{~mW}$. The deflection angle $\theta$ is then recorded (Fig. 4) and shows a linear variation in function of the squared root of the incident mechanical power, that is proportional to the current driving the excitation coil.

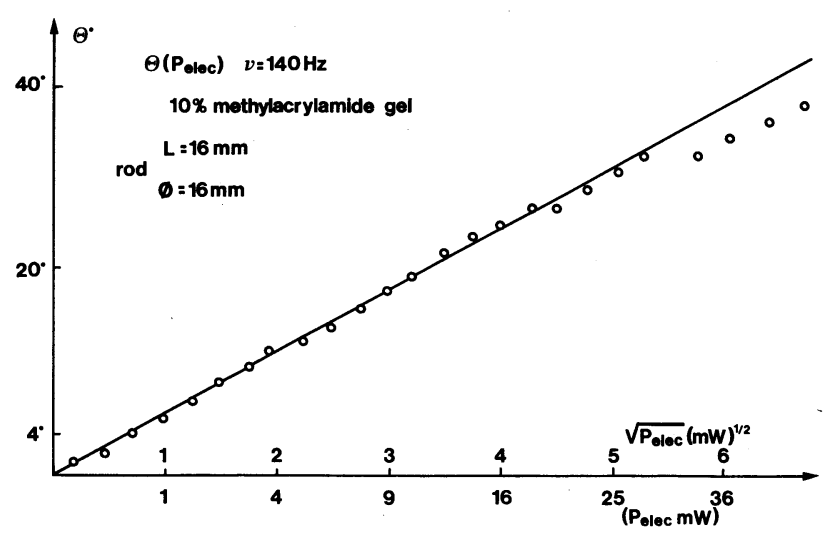

Fig. 4. - Angle of total deflection versus electrical power in the mechanical transducer. The frequency. is for the 2 nd resonance mode of the sample.

5. Applications. - We are going to show here some very simple uses of the deflection mechanism we described : it does not claim to be a review but instead an illustration of the potential applications of the system.

The optical reflexion coefficient is low and it could be more convenient to use the deflection system by transmission which is more complicated to analyse than the reflection geometry, but which allows the full use of the laser power. It gives however a slightly smaller effect. The cylindrical rod shape of the gel is a geometry convenient to study because its great simplicity but the outer beams has a linelike shape which does not fit very well to practical purpose : we use a sample grown in a cube-shape. The resonance modes are more complicated in this geometry than in the rod but if the laser beam is incident in the middle of the face, the outer beam gives a circular point-like image of the screen : when the laser beam is incident on the gel in this symmetrical location, the deflection path is parallel to the $u_{z}$ excitation of the mode.

5.1 LIGHT INTENSITY MODULATION. - The intensity of the outer beam detected at the output of a hole drilled in the screen and located on the path of the deflected spot, is modulated. Two main geometries should be mentioned.

1) A $100 \%$ square-wave modulation of the light intensity is obtained for a hole whose diameter is close to the beam diameter, and for a mechanical power sufficient to deflect the beam in the screen plane on length greater than its diameter. For instance, if the screen is located at $100 \mathrm{~mm}$ of the gel sample, and the 
hole diameter being $0.5 \mathrm{~mm}$, we need $120 \mu \mathrm{W}$ of electric power on the incident transducer at $140 \mathrm{~Hz}$ and around $9 \mathrm{~mW}$ at $1200 \mathrm{~Hz}$. For higher power, the system can work to higher frequencies without difficulties, the only limitation being to keep the mechanical $Q$ value at a few unities.

2) A pinhole the diameter of which is very small compared with the beam diameter will analyse the light intensity distribution inside the beam when it is moving in front of the pinhole. For instance a Gaussian beam with a light intensity angular distribution $\sim \mathrm{e}^{-a \theta^{2}}$ will be analysed by the pinhole when it is deflected as $\theta=\theta_{0} \sin \omega_{0} t, \omega_{0}=$ frequency of the mechanical excitation : the intensity through the pinhole varies as

$$
\mathrm{e}^{-a \theta_{0}^{2} \sin ^{2} \omega_{0} t} \sim a \theta_{0}^{2} \sin ^{2} \omega_{0} t .
$$

The pinhole can be adjusted slightly off-center the beam axis defined without mechanical power, to give a linear variation of the light intensity in function of the excitation frequency. The same principle of modulation has been used in a vibrating mirror system [9] but the small amplitude of vibration does not provide enough modulation of the intensity.

5.2 IMAGE SCANNING. - If the deflected laser beam is made to illuminate a point of an image, the reflected or transmitted intensity of the light gives a signal inversely proportional to the opacity or reflectivity of the image point. With the simple method just described we set up an illuminating system which analyse sequentially a linear image consisting in black and white points. The transmitted light is collected by an optical system which focuses it on a photocell : an analog signal corresponding to the points opacity distribution is obtained. The experimental set-up is shown in figure 5 .

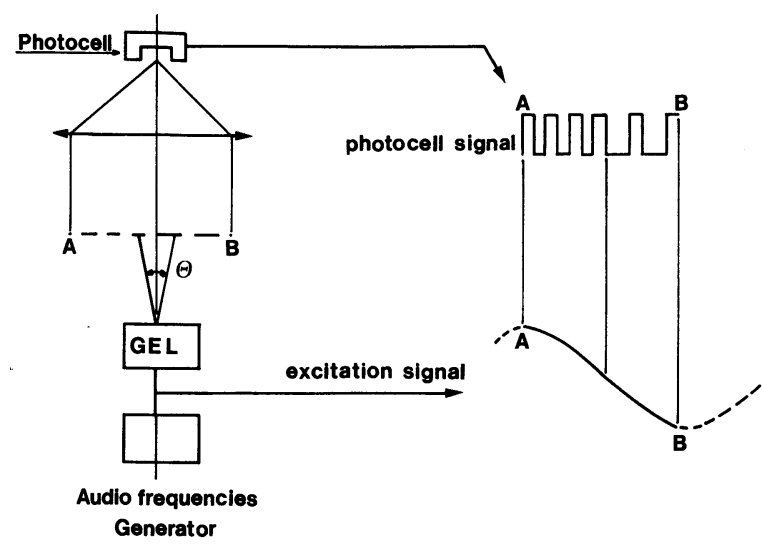

Fig. 5. - Image scanning system. On this example, the image is made of a succession of transparent and black point linearly aligned between the two maximum locations A and B of the deflected spot.

6. Conclusion. - We describe a very simple and low cost system able to deflect a light beam under the influence of mechanical excitation at frequencies between 100 and $2000 \mathrm{~Hz}$.

The device is based on use of the surface deformations of a rod of gel driven at resonance on a dilatational mode. The effect is not particular to gel but is made usable in this media by the very low value of the mode velocity which allowed to obtain important deformation with very low mechanical power.

Positional intensity modulation of a laser beam has been already obtained with device as simple as a mirror bonded on an earphone [9] : the main improvement in the system presented here is the very high deflection angle obtained at low mechanical power allowing, for instance, the image scanning we described.

\section{References}

[1] Fleury, P., J., Principles of polymer chemistry (Cornell University Press) 1953.

[2] Tanaka, T., Hocker, L. O., Benedek, G. B., J. Chem. Phys. 59 (1973) 5151.

[3] Bacri, J.-C., Dumas, J. and Levelut, A., J. Physique Lett. 40 (1979) L-231.

[4] Hecht, A. M., Geissler, E., J. Physique 39 (1978) 631
[5] Redwood, M. R., Mechanical waveguides (Pergamon Press), 1960, chap. 6.

[6] Bancroft, D., Phys. Rev. 59 (1941) 588.

[7] Davies, R. M., Phil. Trans. R. Soc. A 240 (1948).

[8] LANDAU, L. and LifCHiTz, E., Mécanique des fluides (ed. M.I.R., Moscou), chap. 77.

[9] Hsu, D. K., Am. J. Phys. 45 (1977) 1127. 